\title{
Mitigating Psychological Effects of Terrorism and Disaster: An Essential Role for Physicians and Medical Staff
}

\section{Physicians need to not only treat the physical injuries of terror victims but also respond to the psychological needs of patients.}

\author{
Jeffrey T. Mitchell, PhD, CTS
}

"A little help, rationally directed and purposefully focused at a strategic time is more effective than more extensive help given at a period of less emotional accessibility."

-Lydia Rapoport, 1962 (crisis intervention theorist and associate professor, School of Social Welfare, University of California)

Physicians and other medical personnel have an enormous opportunity, an obligation, and, indeed, the privilege to provide brief, timely, and simple crisis interventions that can make a remarkable difference in their patients' lives. Too many people have been discharged from hospitals with their organs repaired, their lacerations sutured, and their bones set, only to continue to suffer painful, and sometimes debilitating, psychological effects generated by their exposure to threatening, physically damaging, and psychologically overwhelming traumatic events.

Virtually 100 percent of people exposed to severe, life-threatening, traumatic events such as acts of terrorism, natural and technological disasters, and significant personal injuries experience some degree of psychological distress [1]. Overall, approximately 9 percent of people exposed to a relatively small but powerful traumatic event develop posttraumatic stress disorder (PTSD) [2]. In disaster situations, however, the rate of PTSD is considerably higher, about 34 percent [3]. About 49 percent of sexual assault victims and 53 percent of torture and kidnapping victims develop PTSD [4].

Valuable lessons have been learned from disasters and terrorist events. In the sarin gas attack in Tokyo, for instance, a huge influx of patients entered emergency rooms. Approximately 1000 people sustained respiratory distress, lacerations, bruises, or muscular-skeletal injuries. An additional 4000 physically uninjured victims of the attack showed up in emergency rooms exhibiting considerable psychological distress characterized by high anxiety and mental confusion [5]. Few medical facilities are prepared to manage such unusual patient loads. Worse yet, few physicians and other medical personnel are adequately trained to manage the psychological impact of tragedies experienced by these patients. Nonetheless, seemingly small efforts by physicians may have huge positive effects on crisis victims.

Victims of terrorist events and disasters have several important needs. Of course, they need care for their physical injuries and illnesses. But they also need shelter, food, security, transportation, and emotional support in the form of contact with their loved ones, good listening, accurate information, practical guidance, clear instructions, appropriate reassurance, and encouragement to engage in adaptive behaviors. Some of those needs can easily be fulfilled by nonpsychiatric health care professionals. It is quite rare for disaster victims to need psychiatric intervention such as medication, hospitalization, or psychotherapy, especially in the early and most acute phases of the disaster. 
Leaving the required psychological support of patients to social work departments or to psychiatrists is, in essence, an abdication of one's responsibilities to care for the entire patient. Victims of disasters and terrorist events are often in a state of psychological shock and need the expertise, guidance, and leadership of physicians. Even in basic first aid texts, part of the treatment for psychological shock is to provide reassurance. The texts do not say "call the psychiatrist to provide reassurance." They say, reassure the victim.

In any case, there are insufficient numbers of mental health professionals who can be called upon to provide the simple things people need most when experiencing an emotional crisis. Most patients would resent the introduction of psychiatric personnel into their care if all they really needed was information and guidance. They would most likely view such an unwarranted insertion of psychiatric personnel into their lives as intrusive and an indication that they are not being taken seriously.

\section{Crisis Intervention Techniques}

Crisis intervention or emotional first aid is, therefore, the responsibility of the primary physician and the immediate medical staff. Crisis intervention is a temporary, active, and supportive entry into an individual's life during a distressing experience. It is not psychotherapy, nor is it a substitute for psychotherapy. It is a common sense approach to supporting people who are struggling through a difficult time. It is based on 7 core principles. They are: (1) simplicity, (2) brevity, (3) innovation, (4) pragmatism, (5) proximity, (6) immediacy, and (7) positive expectancy.

These principles are easy to apply to injured or ill patients, and most of them can be implemented through simple tactics that do not require a great deal of additional training. Start by listening carefully to your patients. Ask them what they need most. Do not be afraid to ask them about their most pressing concerns. Keep in mind that the most powerful tool available to a physician serving the victims of a terrorist event or a disaster is accurate, current information. A patient's anxiety tends to decrease when he or she is presented with factual information. Even bad news can lower tension and anxiety if it is presented with care, concern, sensitivity, and honesty.

Warn people about what you need to do for them before initiating medical procedures. Spend a little more time with distressed people. Sometimes a few extra seconds can count. Avoid sending a messenger, and tell them the most important information yourself. Connect people with their loved ones whenever possible. Keep instructions simple, brief, and practical. Express your understanding, concern, and sympathy.

If a major event overwhelms the facility, consider calling one of the many voluntary CISM teams. They are coordinated through the nonprofit, International Critical Incident Stress Foundation and can often provide assistance in managing the needs of disaster victims or the medical facility staff. The ICISF coordination center can be reached 24 hours a day at (410) 313-2473 for emergencies or (410) 750-9600 for routine calls.

\section{References}

1. Everly GS Jr, Lating JM. Personality-Guided Therapy for Posttraumatic Stress Disorder. Washington, DC: The American Psychological Association; 2004.

Google Scholar

2. US Department of Health and Human Services. Mental Health: A Report of the Surgeon General. Rockville, Md: Center for Mental Health Services, US Department of Health and Human Services; 1999.

Google Scholar

3. North $\mathrm{C}$, Nixon S, Shariat S, et al. Psychiatric disorders among survivors of the Oklahoma City bombing. JAMA. 1999;282:755-762.

View Article PubMed Google Scholar

4. Breslau N, Kessler RC, Chilcoat HD, Schultz LR, Davis GC, Andreski P. Trauma and posttraumatic stress disorder in the community. Arch Gen Psychiatry. 1998;55:626-633.

View Article PubMed Google Scholar 
5. Ohbu S, Yamashina A, Takasu N, et al. Sarin poisoning on the Tokyo subway. South Med J. 1997;90:587-593. View Article PubMed Google Scholar

Jeffrey T. Mitchell, PhD, is a certified trauma specialist and a clinical associate professor of emergency health services at the University of Maryland. He is a cofounder and former president of the International Critical Incident Stress Foundation, a nonprofit organization that provides traumatic stress education and support services to emergency personnel.

The viewpoints expressed on this site are those of the authors and do not necessarily reflect the views and policies of the AMA.

(C) 2004 American Medical Association. All Rights Reserved. 